\title{
Characterisation of a new group of Francisella tularensis subsp. holarctica in Switzerland with altered antimicrobial susceptibilities, 1996 to 2013
}

F C Origgi ${ }^{1,2}$, J Frey ${ }^{1}$, P Pilo (paola.pilo@vetsuisse.unibe.ch) ${ }^{1}$

1. Institute of Veterinary Bacteriology, Vetsuisse Faculty, University of Bern, Bern, Switzerland

2. Centre for Fish and Wildlife Health, Vetsuisse Faculty, University of Bern, Bern, Switzerland

Molecular analysis of Francisella tularensis subsp. holarctica isolates from humans and animals revealed the presence of two subgroups belonging to the phylogenetic groups B.FTNFo02-00 and B.13 in Switzerland. This finding suggests a broader spread of this group in Europe than previously reported. Until recently, only strains belonging to the Western European cluster (group B.FTNFo02-00) had been isolated from tularaemia cases in Switzerland. The endemic strains belonging to group B.FTNFo02-00 are sensitive to erythromycin, in contrast to the strains of the newly detected group B.13 that are resistant to this antibiotic. All the strains tested were susceptible to ciprofloxacin, streptomycin, gentamicin, nalidixic acid and chloramphenicol but showed reduced susceptibility to tetracycline when tested in a growth medium supplemented with divalent cations. The data show a previously undetected spread of group B.13 westwards in Europe, associated with changes in the antibiotic resistance profile relevant to treatment of tularaemia.

\section{Introduction}

Francisella tularensis is a Gram-negative bacterium causing the zoonotic disease tularaemia. The two clinically relevant subspecies are $F$. tularensis subsp. tularensis and $F$. tularensis subsp. holarctica. Of the two, only the latter subspecies is present in Europe. Human infections mainly occur through inhalation, ingestion, or by direct contact with infected animal species and contaminated animal tissues, water and aerosols [1]. In general, it is difficult to trace the source of infection [2]. Analyses of molecular genetic markers of the strains circulating in the environment provide valuable information on the dynamics of infection in people and in animals, and improve the knowledge of the biology of this bacterium. Genetic and phenotypic data are also necessary to determine the most suitable antimicrobial substances to use to treat humans and animals [3-8].
With the recent growing interest in $F$. tularensis biology, several tools have been developed to investigate the molecular epidemiology of this genetically monomorphic bacterium following a hierarchical scheme [9-13]. Genomes of different strains are screened for canonical single nucleotide polymorphism (canSNP) signatures. With the advent of novel technologies, an increasing number of strains are sequenced, leading to the discovery of new canSNP markers and signatures specific to new subgroups. The growing information involves adjustments in the phylogenetic nomenclature of $F$. tularensis and allows better resolution within the subgroups $[11,12,14]$. Throughout this manuscript, we will follow the nomenclature based on the canSNPs (for nomenclature clarity, refer to schema in Figure 1). In Europe, strains belonging to groups B.13 and B.FTNFoo2-0o are those predominantly isolated [12]. The group B.13 extends geographically from Scandinavia to the eastern European rim, with co-circulation of several of its subgroups in some countries. In Western Europe, a specific group, B.FTNFoo2-0o, is circulating in France, Germany, Italy, Spain and Switzerland [11-19]. Recently, it was observed that Germany represents a geographical diaphragm virtually separating group B.13 from group B.FTNFo02-00 [18].

Interestingly, strains belonging to group B.FTNFoo2-00 are described as sensitive to erythromycin, whereas strains belonging to other groups show variability in this marker $[3-5,7,18]$. Historically, strains of $F$. tularensis subsp. holarctica have been separated in two biovars: biovar I, strains sensitive to erythromycin, and biovar II, strains resistant to erythromycin [20]. Although this marker is principally used for epidemiological purposes, there may be significant clinical implications in areas with co-circulation of different groups. A paradigmatic example of this is the recent recommendation of treating pregnant women infected with $F$. tularensis with azithromycin in geographical 
Schematic of Francisella tularensis subsp. holarctica nomenclature based on canonical single nucleotide polymorphisms

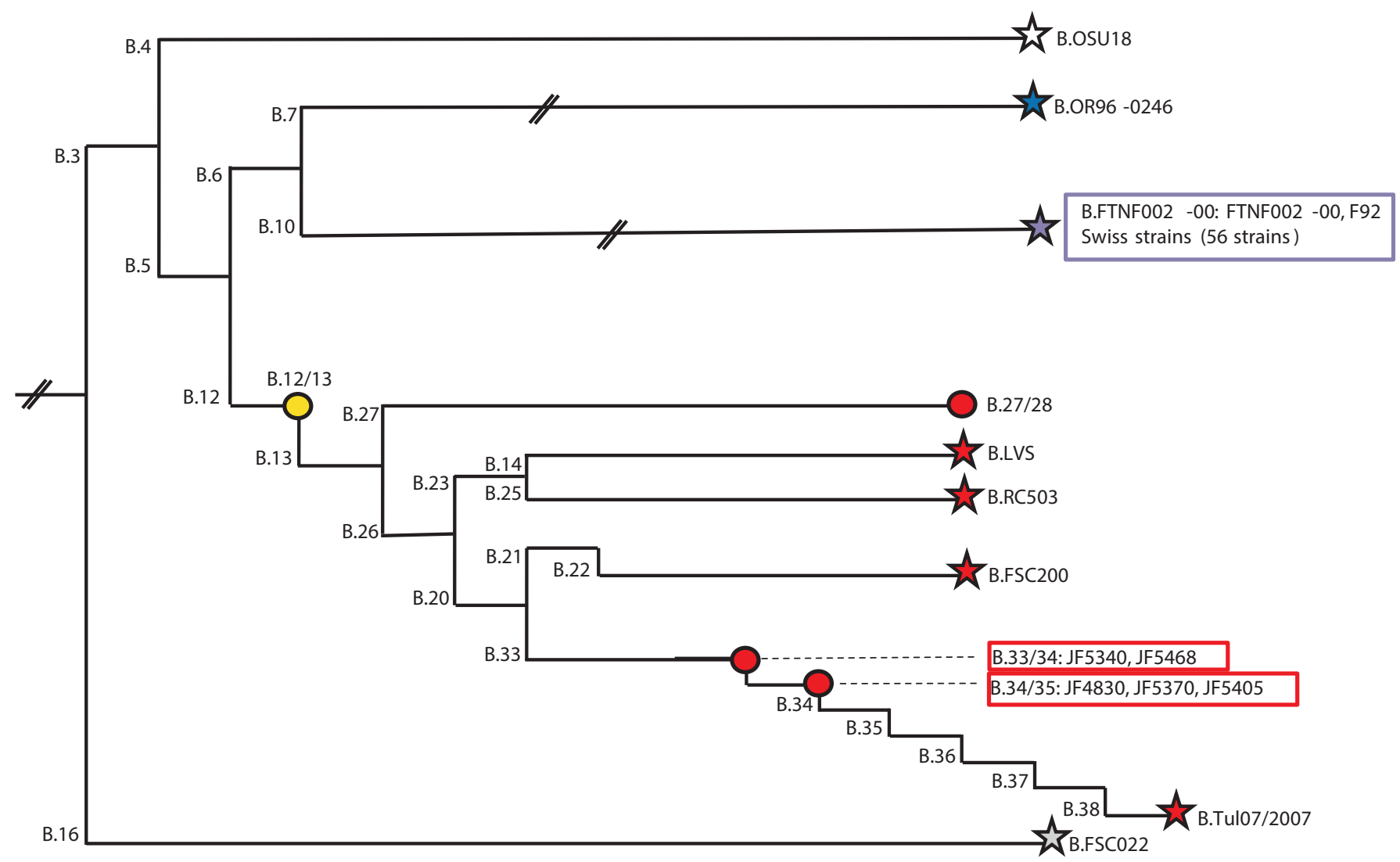

Canonical single nucleotide polymorphisms (canSNP), adapted from and according to the colours and symbols previously described [11-13], showing the position of Swiss strains within the subspecies. Stars represent terminal subgroups (sequenced strains), while circles indicate collapsed branches. The length of branches is not scaled. Only canSNP relevant to this study are presented to clarify the phylogenetic

position of groups and subgroups discussed. Parallel bars indicate missing intermediate canSNPs and corresponding nodes and branches. CanSNPs are indicated to the left of the nodes. Strains for which whole-genome sequencing information is available and which were used for comparisons, are highlighted in bold at the end of the branches. Groups and subgroups identified in this study are boxed. Dashed lines do not represent branches.

areas where strains sensitive to erythromycin are circulating [21].

This study describes the first isolation of erythromycin-resistant strains of $F$. tularensis subsp. holarctica belonging to group B.13 in Switzerland. We discuss how these findings impact on the phylogeography of F. tularensis subsp. holarctica in Europe and on antibiotic treatment of affected individuals living in areas with co-circulating groups [12].

\section{Methods}

Bacterial strains, DNA templates, identification and typing

All manipulations with live cultures were performed in a $\mathrm{BSL} 3$ containment laboratory. F. tularensis strains were cultivated on chocolate agars with IsoVitaleX (Becton Dickinson, Allschwil, Switzerland) for three days at 37 ${ }^{\circ} \mathrm{C}$ with $5 \% \mathrm{CO}_{2}$. Lysates from cultures were prepared, filter-sterilised [22] and tested by real-time PCR for the presence of the fopA gene to confirm the species
F. tularensis $[22,23]$. The subspecies was subsequently determined by amplification of the region of difference (RD)1 [24]. Strains were further characterised by PCR for the presence of deletions in two different markers, RD23 and Ft-M24, specific to the group B.FTNFoo2-00 $[16,17,24]$ and by multilocus variable-number tandem repeat (VNTR) analysis (MLVA) with six VNTRs markers (Ft-M3, Ft-M6, Ft-M20, Ft-M21, Ft-M22 and Ft-M24) $[17,25]$. The MLVA results were further confirmed by analysis of the following canSNP markers B.11, B.12 B.20, B.21, B.22, B.23 and B.33 to B.38 $[11,12]$.

\section{Minimal inhibitory concentrations of antimicrobial agents}

The minimal inhibitory concentration (MIC) values of antibiotic drugs relevant to clinical use such as gentamicin (0.12-16 mg/L), streptomycin (1-16 mg/L), ciprofloxacin (0.06-4 mg/L), tetracycline (0.25-16 $\mathrm{mg} / \mathrm{L})$, nalidixic acid $(2-64 \mathrm{mg} / \mathrm{L})$, chloramphenicol (2-32 mg/L) and erythromycin (0.5-32 mg/L), were determined in two different broth media: (i) modified Cation-Adjusted Mueller Hinton Broth (mCAMHB): 
Cation-Adjusted Mueller Hinton Broth (Becton Dickinson, Heidelberg, Germany) supplemented with 2\% PolyViteX Enrichment (BioMérieux, Marcy l'Etoile, France), and (ii) modified Mueller Hinton II (mMHII) broth: $\mathrm{mCAMHB}$ with $0.1 \%$ glucose, $63 \mathrm{mM} \mathrm{CaCl}$, $53 \mathrm{mM} \mathrm{MgCl}$ and $34 \mathrm{mM}$ ferric pyrophosphate using custom 96-well Sensititre susceptibility plates (Trek Diagnostics Systems, East-Grinstead, England and MCS Diagnostics BV, JL Swalmen, the Netherlands), according to the Clinical and Laboratory Standards Institute (CLSI) guidelines [26] and the informational supplement [27]. Antibiotics of the class of the betalactams were not tested because of the known natural resistance of $F$. tularensis strains to these antimicrobial substances $[6,28]$. The 96 -well plates were incubated at $37{ }^{\circ} \mathrm{C}$ in $5 \% \mathrm{CO}_{2}$ atmosphere for 48 hours. The MIC values were defined as the lowest concentration exhibiting no visible growth. MICs were read after 24 and 48 hours incubation. For quality assurance, the reference strains of Escherichia coli ATCC 25922 and Staphylococcus aureus ATCC 29213 were also tested by broth microdilution in $\mathrm{mMHII}$ broth and in $\mathrm{mCAMHB}$.

\section{Genetic characterisation of erythromycin resistance}

The genetic characterisation of erythromycin resistance was carried out by PCR amplification and further sequencing of the genes encoding for the $23 \mathrm{~S}$ rRNA $(r r l)$, the L4 $(r p l D)$ and L22 ( $r p l V)$ ribosomal proteins as previously described by Gestin and colleagues [29]. The sequences obtained were edited, aligned and compared in Sequencher (GeneCodes, Ann Arbor, United States) with the corresponding genes of the completely sequenced strains FTNFo02-00 (group B.FTNFo02-00, isolated in France [16]), F92 (group B.FTNFoo2-00, isolated in Germany [30]), FSC200 (group B.13, isolated in Sweden [31]) and LVS (group B.13, isolated in Russia) (NCBI/GenBank accession numbers: CPooo803, CPoo3932, CPoo3862 and AM233362, respectively).

\section{Results}

Sixty-one strains were isolated between 1996 and 2013 from human and animal cases of tularaemia from a representative area of the Swiss territory (Table 1, Figure 2). Thirteen strains isolated before 2009 (JF3820, JF3821, JF3822, JF3824, JF3825, JF3826, JF3828, JF3829, JF3859, JF4092, JF4128, JF4212 and JF4242) had previously been characterised as $F$. tularensis subsp. holarctica belonging to group B.FTNFoo2-0o [17]. All other strains $(n=48)$ were identified here as $F$. tularensis subsp. holarctica, and 43 of them were determined as group B.FTNFo02-0o (Table 1) [17], while five strains JF4830, JF5340, JF5370, JF5405 and JF5468 did not harbour the deletions specific to the group B.FTNFo02-00 in the RD23 and Ft-M24 markers. MLVA confirmed the clustering of the 56 strains (isolated between 1996 and 2013) belonging to group B.FTNFoo2-0o (data not shown). The highest variability among the markers used for MLVA was observed within markers Ft-M3 and Ft-M6 as previously reported for the group B.FTNFoo2-0o (Table
1) $[15,17,18]$. Concerning the strains not belonging to group B.FTNFo02-00, the three strains, JF5340, JF5370 and $\mathrm{JF}_{5405}$ isolated from two human patients and one hare between 2012 and 2013, shared the same VNTR profile, while strains JF4830, isolated in 2010 from a patient returning from a vacation in eastern Europe (possibly corresponding to an imported case), and JF5468, isolated from a hare in 2013, revealed a distinct VNTR profile, with one variation in the Ft-M3 marker (Table 1). The four strains, JF5340, JF5370, JF5405 and JF5468 were isolated from a large geographical area of Switzerland extending from the central west to the east sides of the country (Figure 2).

CanSNP analyses were performed on a panel of 24 representative strains (shaded in grey in Table 1). All strains belonging to group B.FTNFo02-00 and harbouring the specific deletions within markers RD23 and Ft-M24 showed the canSNP profile characteristic of the group B.FTNFo02-00 (Table 1) [11,32]. All other strains (JF4830, JF5340, JF5370, JF5405 and JF5468) had a canSNP profile not corresponding to group B.FTNFoo2-00 (Table 1) [11]. In order to further characterise the strains not belonging to group B.FTNFo02-00, the canSNP markers B.21, B.22 and B.23 were sequenced. They showed the SNP profile corresponding to group B.13 according to the genotypes described by Svensson et al. (Table 1) [11,32]. Moreover, a higher resolution of the genetic characterisation of the strains in group B.13 was obtained through analysis of the canSNP markers B.33 to B.38 [12]. Two subgroups were observed: the B.33/34 (JF5468 and JF5340) and the B.34/35 (JF4830, JF5370 and JF5405) according to the nomenclature described by Gyuranecz et al. [12] (Table 1 and Figure 1).

Antibiotic susceptibility profiles were determined for the panel of 24 representative strains (Table 2 ) by broth microdilution method using two broth media, mCAMHB and $\mathrm{mMHII}$, for seven antibiotic drugs and read after 48 hours. The $F$. tularensis strains did not show any visible growth at the concentrations tested for nalidixic acid, chloramphenicol and ciprofloxacin in either broth medium, tested (Table 2). The MIC values for chloramphenicol and ciprofloxacin were below the breakpoint values provided in the CLSI guidelines, $\leq 8 \mu \mathrm{g} / \mathrm{mL}$ for chloramphenicol and $\leq 0.5 \mu \mathrm{g} / \mathrm{mL}$ for ciprofloxacin, while no breakpoint value is available for nalidixic acid [27]. MIC values for gentamicin ranged between 1 and $4 \mu \mathrm{g} / \mathrm{mL}$ in $\mathrm{mMHII}$, but between $\leq 0.12$ and $0.25 \mu \mathrm{g} / \mathrm{mL}$ in $\mathrm{mCAMHB}$. The breakpoint value for gentamicin given in the CLSI guidelines for $F$. tularensis is $\leq 4 \mu \mathrm{g} / \mathrm{mL}$ [27]. The discrepancy in the MIC values observed for gentamicin between cultures of $F$. tularensis in $\mathrm{mMHII}$ and $\mathrm{mCAMHB}$ was confirmed for reference strains $E$. coli ATCC 25922 and S. aureus ATCC 29213 (Table 2). MIC values for streptomycin ranged between 2 and 4 $\mu \mathrm{g} / \mathrm{mL}$ in $\mathrm{mMHII}$ and were all at $4 \mu \mathrm{g} / \mathrm{mL}$ in $\mathrm{mCAMHB}$ (Table 2). The breakpoint value provided for streptomycin in the CLSI guidelines is $\leq 16 \mu \mathrm{g} / \mathrm{mL}$ when testing is performed in a $\mathrm{CO}_{2}$ atmosphere [27]. MIC values for 

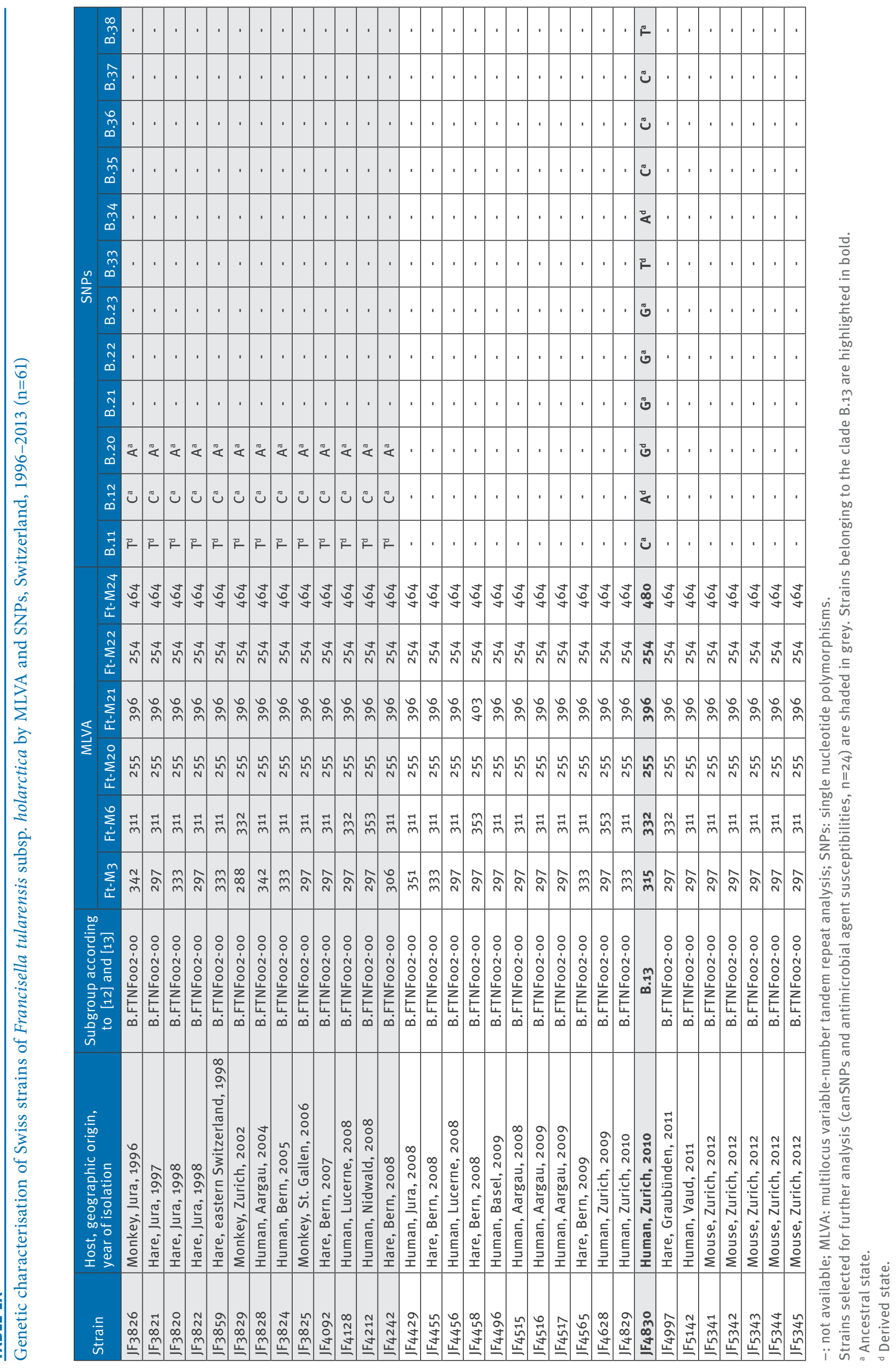


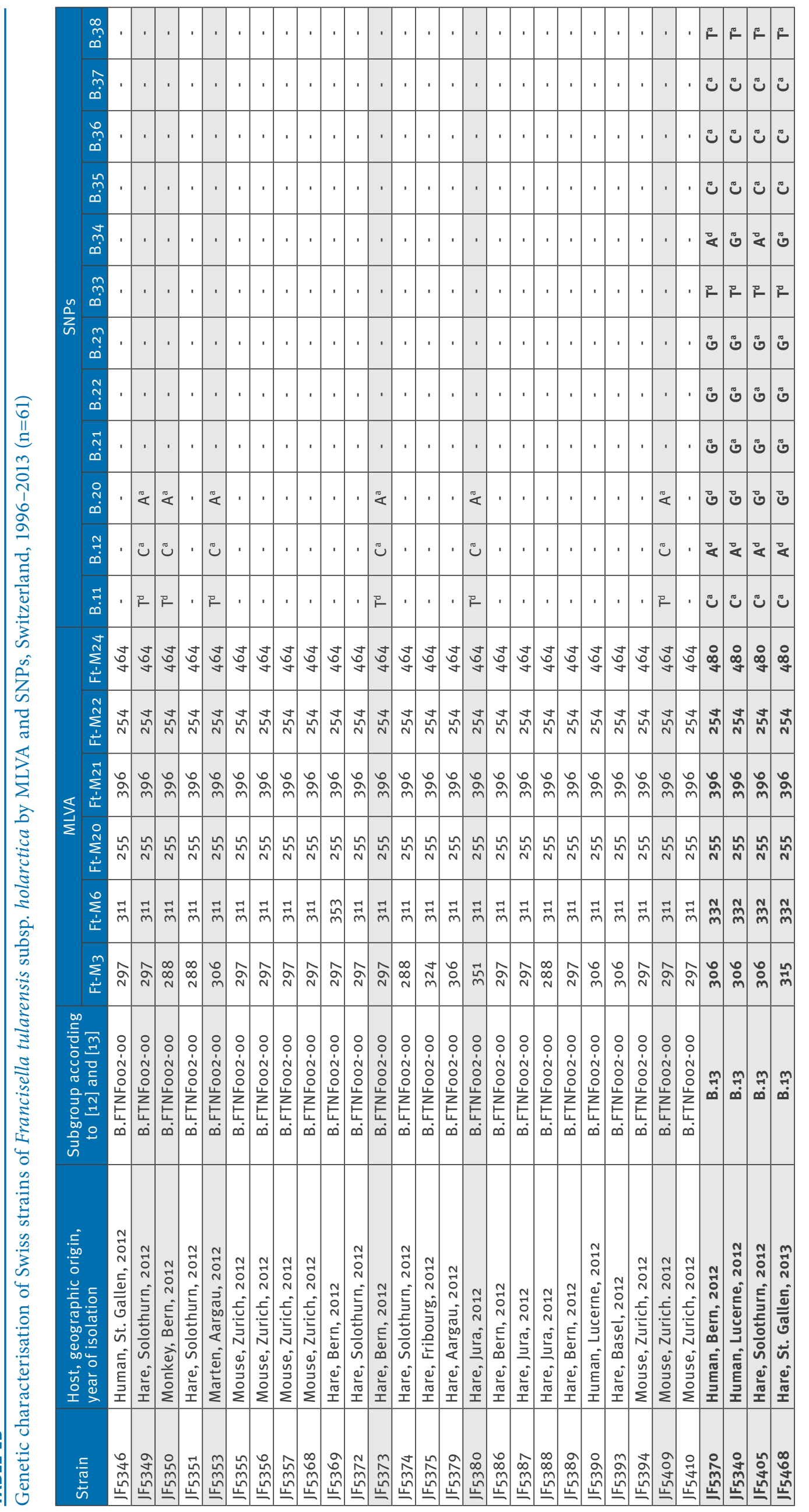

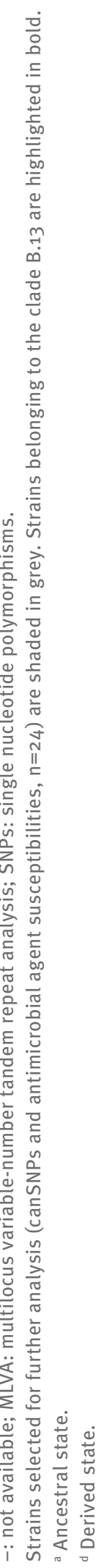




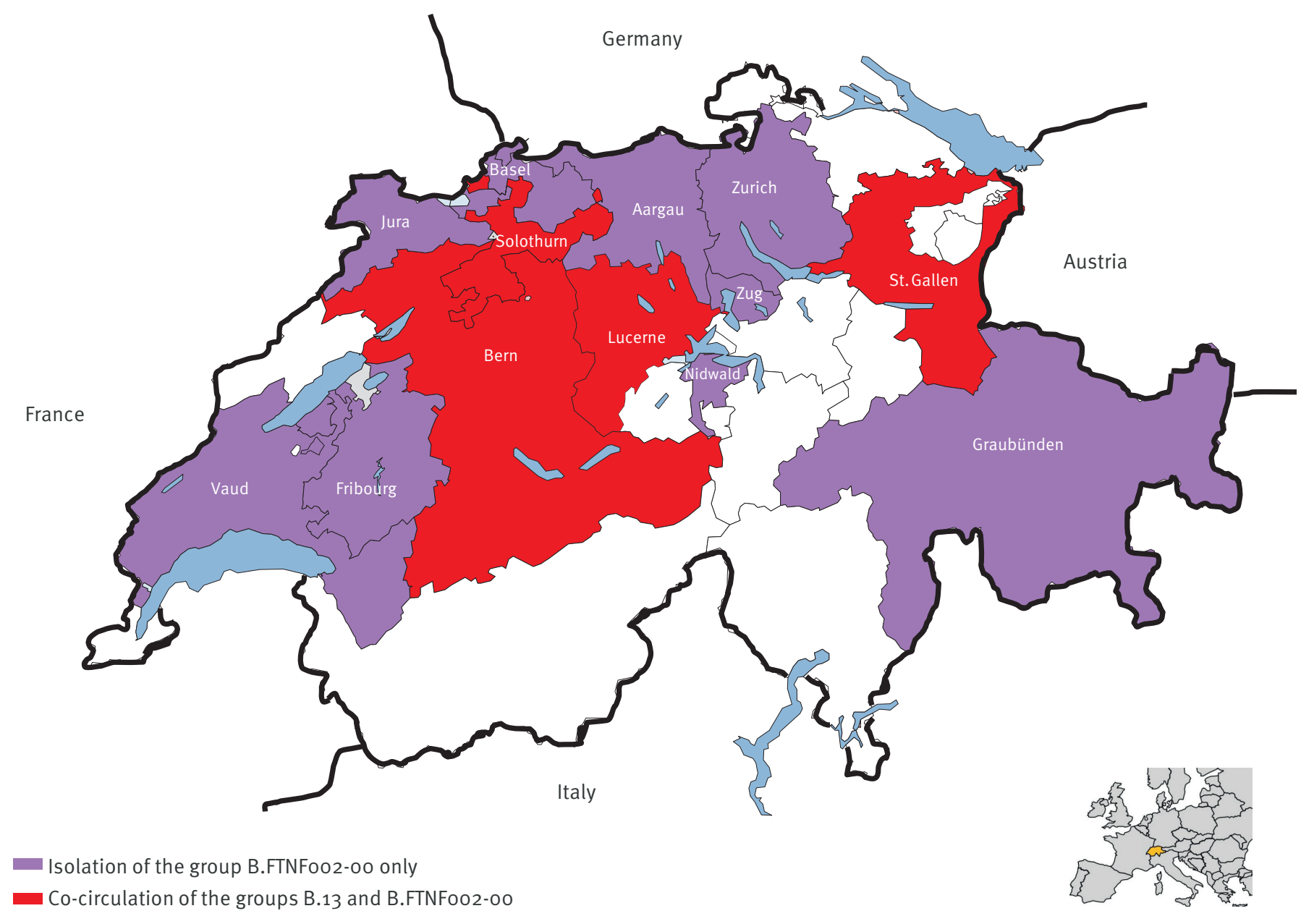

Cantons where both groups B.FTNFo02-00 and B.13 were circulating are coloured in red, while cantons where only the group B.FTNFo02-00 was isolated are coloured in purple.

Map background downloaded from http://www.presentationmagazine.com/

tetracycline ranged between 2 and $8 \mu \mathrm{g} / \mathrm{mL}$ in $\mathrm{mMHII}$, but were all $\leq 0.25 \mu \mathrm{g} / \mathrm{mL}$ in $\mathrm{mCAMHB}$ (Table 2). For this reason, MIC values for tetracycline were also tested by Etest in order to confirm the results obtained with mCAMHB. With this method, MIC values for tetracycline ranged between 0.19 and $0.38 \mu \mathrm{g} / \mathrm{mL}$, which was similar to the ones measured by broth microdilution method with mCAMHB (Table 2). The breakpoint value given in the CLSI guidelines for tetracycline is $\leq 4 \mu \mathrm{g} /$ $\mathrm{mL}$ [27]. Moreover, a difference in MIC values for tetracycline in $\mathrm{MMHII}$ and $\mathrm{mCAMHB}$ was also observed for reference strains $E$. coli ATCC 25922 and S. aureus ATCC 29213 (Table 2). MIC values for erythromycin exhibited a bimodal distribution: Strains belonging to group B.13 exhibited erythromycin resistance with MIC values higher than $32 \mu \mathrm{g} / \mathrm{mL}$, while all the strains belonging to group B.FTNFo02-0o were sensitive to erythromycin, showing MIC values ranging from 1 to $8 \mu \mathrm{g} / \mathrm{mL}$ (Table 2). However, no breakpoint value for $F$. tularensis is provided for any macrolides in the CLSI guidelines [27].
Genetic characterisation of erythromycin resistance was performed by PCR amplification and sequencing of the three copies of the $r r l$ gene and of the $r p l D$ and the rplV genes of the five strains showing phenotypic resistance to erythromycin and belonging to group B.13 (JF4830, JF5340, JF5370, JF5405 and JF5468). The sequences were compared to the corresponding genes of strains FTNFoo2-00 (group B.FTNFoo2-00), F92 (group B.FTNFoo2-0o), FSC200 (group B.13) and LVS (group B.13). All five strains isolated in Switzerland, belonging to group B.13 and showing phenotypic resistance to erythromycin, had two mutations in all three copies of the $r r l$ gene when compared to the available sequences of the strains FTNFo02-00 and F92 of the group B.FTNFo02-00. The first mutation was detected in domain I of the $r r l$ gene, A453G (E. coli numbering), while the second mutation was observed in domain $\mathrm{V}$ of the $r r l$ gene, A2059C (E. coli numbering). A silent mutation $\mathrm{G}$ to $\mathrm{A}$ at the third position of codon 181 ( $E$. coli numbering) was found in the rplD gene encoding 


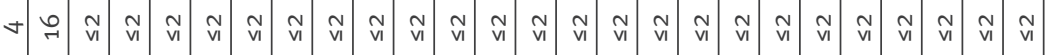

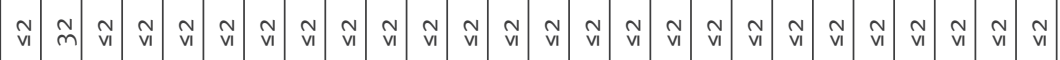

庹

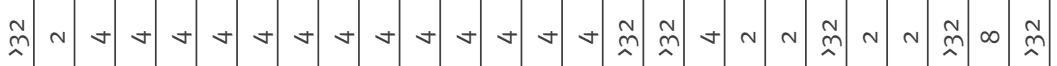

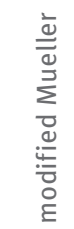

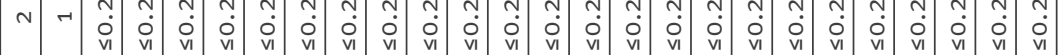

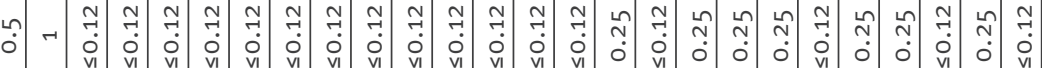

席

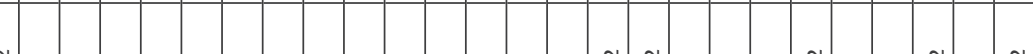

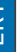

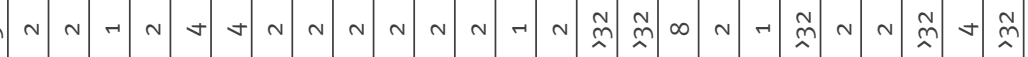

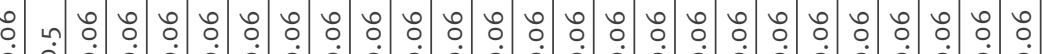

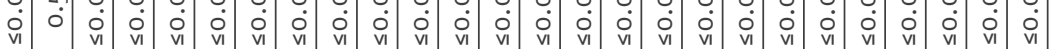

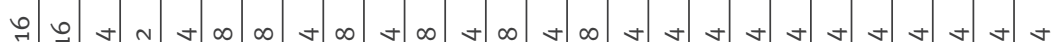

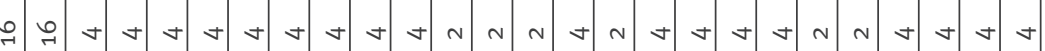



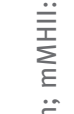
高 芩

âd 
for the ribosomal protein L4, while no mutation was detected in the rplV gene encoding for the ribosomal protein L22. These mutations observed in Swiss strains belonging to group B.13 were exactly the same as those of the strain LVS and FSC200 belonging to group B.13.

The EMBL/GenBank accession numbers for the nucleotide sequences of the $r r l$, the $r p l D$ and the $r p l V$ genes are: KF712467, KF712466 and KF712465, respectively.

\section{Discussion}

This study describes the characterisation of $F$. tularensis strains isolated in Switzerland during the last 17 years. Until 2012 , only strains belonging to group B.FTNFo02-0o have been isolated in Switzerland from humans and animals. A single exception is strain JF4830 that was isolated from a human patient in 2010, who most probably acquired the infection travelling in eastern Europe. The new strains JF5340 and JF5370 were isolated from human patients with no history of travelling abroad for several months before the appearance of the first tularaemia-associated symptoms. The only exception is a stay at Lago Maggiore in Italy, at the border to Switzerland, a month before the initial symptoms, for the patient infected with strain JF5340. Strains JF5405 and JF5468 were isolated from the carcass of two wild hares in 2013. All four strains (JF5340, JF5370, JF5405 and JF5468) belonged to group B.13 and resolved with distinct MLVA profiles (Table 1). Moreover, the analysis of canSNP B.33 to B.38 led to identification of the subgroups B.33/34 and B. 34/35 previously described by Gyuranecz et al. [12]. Both subgroups were isolated in central and eastern Europe and from countries bordering Switzerland, such as Austria and Germany, but not from countries east of Romania [12]. Moreover, the subgroup B.33/34 is also known to be circulating in Sweden [12].

These findings reveal that group B.13 is currently circulating in Switzerland in the same areas as strains of group B.FTNFoo2-0o (Figure 2) and are affecting both human patients and free-ranging animals. This is in contrast to neighbouring Germany, where a strict separation between groups was described [18]. Strains isolated between 1996 and 2011 from humans, hares and captive non-human primates all belonged to group B.FTNFo02-00. Because of the small number of strains isolated between 1996 and 2008, it is difficult to draw conclusions about a recent introduction of strains belonging to group B.13 or a long-lasting co-circulation of both groups following the expansion of group B.FTNFo02-00 of $F$. tularensis subsp. holarctica.

Strains belonging to group B.FTNFo02-00 are known to be sensitive to erythromycin $[7,29,33]$. Also the Swiss $F$. tularensis subsp. holarctica strains belonging to group B.FTNFo02-0o are sensitive to erythromycin, while the new strains belonging to group B.13 are resistant (Table 2). Since strains resistant to erythromycin are actually circulating in Switzerland, macrolides are not recommended for the treatment of cases of tularaemia acquired in Switzerland and possibly also in neighbouring areas unless analysis of the infecting strains reveals sensitivity to this antibiotic. Because of the toxicity of recommended antibiotics against tularaemia for pregnant women and foetuses, Dentan et al. [21] proposed to treat it, in areas where the group B.FTNF002-00 is endemic, with a macrolide, more specifically with azithromycin. However, the spread to western Europe of strains resistant to macrolides poses serious concerns and needs to be carefully considered by the clinicians when facing a therapeutic choice in this context. Several studies suggest that strains of F. tularensis from western Europe are sensitive to macrolides $[4,7,18,29,33,34]$.

Genetic analysis of the strains resistant to erythromycin revealed two mutations in the three copies of the $\mathrm{rrl}$ gene and a silent mutation in the $r l p D$ gene encoding the ribosomal protein L4, compared with the strains belonging to group B.FTNFoo2-00: FTNFo02-00 and F92. Interestingly, the same mutations are present in the strains LVS and FSC200, both belonging to group B.13. This finding may suggest that these mutations are shared among subgroups belonging to B.13 and may have appeared in a common ancestor. However, this hypothesis should be validated by testing a larger panel of strains.

Broth microdilution testing was performed in $\mathrm{mMHII}$ broth and in mCAMHB $[4,7]$. Results were compatible for all antibiotics tested in both media except for the MIC values recorded for gentamicin and tetracycline that showed higher values in $\mathrm{mMHII}$ broth than in mCAMHB (Table 2). This discrepancy was confirmed by testing the reference strains, E. coli ATCC 25922 and S. aureus ATCC 29213, which also showed higher MIC values for gentamicin and tetracycline in mMHII broth than the quality control ranges for broth microdilution method in $\mathrm{mCAMHB}$ reported in the CSLI guidelines [27], confirming that MIC values for these two antibiotics are higher using mMHII broth than mCAMHB (Table 2). High MIC values of reference strains for gentamicin and to a lesser extent for tetracycline tested in $\mathrm{mMHII}$ broth were previously described by Baker et al. [35]. They explained these results to be due to the addition of the bivalent cations $\mathrm{Ca}^{2+}$ and $\mathrm{Mg}^{2+}$ in the medium. MIC values for tetracycline were within the range considered clinically effective when tested with $\mathrm{mCAMHB}$ and by Etest. Nevertheless, given the high number of tularaemia cases for whom tetracycline-associated treatment failure has been described, including doxycycline [36-39], these antibiotics are not recommended in case of infection with $F$. tularensis.

MIC values for gentamicin, chloramphenicol, streptomycin and ciprofloxacin were within the range indicative of clinical efficacy in both media, although MIC values of four strains for gentamicin in $\mathrm{mMHII}$ were very close to the breakpoint value given in the CLSI guidelines [27]. Ciprofloxacin showed the lowest MIC values and prevented growth of all strains at $0.06 \mu \mathrm{g} /$ 
$\mathrm{mL}$. The finding is consistent with previous reports on type A and type B tularaemia [5, 40-44] and supports the experience that ciprofloxacin may be an attractive treatment option for tularaemia [37].

\section{Conclusion}

In conclusion, at least two groups of $F$. tularensis subsp. holarctica are currently co-circulating in Switzerland. Of these, the group B.FTNFoo2-0o seems to be more prevalent and has been identified in tularaemia cases since 1996, while B.13 was less commonly isolated in Switzerland and not before 2012. Since strains belonging to the subgroups B.33/34 and B.34/35 are erythromycin-resistant, this antibiotic is not recommended to treat cases of tularaemia acquired in Switzerland without prior typing of the strains. These concerns should also apply in countries where the group B.FTNFoo2-00 seems to be prevalent given that the exact limits of the co-circulation areas are not known. The mutations resulting in erythromycin resistance in group B.13 strains are exactly the same as those present in the strain LVS belonging to the same group. Further investigations are warranted in order to understand if they are shared by all strains of the group B.13. In view of the in vitro results and of previous clinical observations, tetracyclines should not be a first choice of treatment for tularaemia, while ciprofloxacin appears suitable for tularaemia treatment. Moreover, because of the fastidious growth requirements of $F$. tularensis, supplements always need to be added to growth media to test antibiotic susceptibility [7,35]. Recently, Georgi et al. published the validation of a protocol for a broth microdilution method (medium not supplemented with divalent cations) for $F$. tularensis [4]. The use of a medium without supplemented divalent cations, mCAMH, has been compared with the previously described methods using mMHII broth (medium supplemented with divalent cations). Considering the discrepancy in the MIC values measured for gentamicin and tetracycline depending on the broth used, it is considered more appropriate the use of mCAMHB for antimicrobial testing of $F$. tularensis strains because it achieves results, at least relatively to some antimicrobial substances, that are less ambiguous than those achieved with the mMHII broth.

\section{Acknowledgements}

The valuable advices on antimicrobial susceptibility assay from Vincent Perreten, Institute of Veterinary Bacteriology, Vetsuisse Fakultät, Universität Bern, are appreciated. The sending of human strains by diagnostic laboratories is acknowledged. Lisa Harwood is sincerely thanked for editing the manuscript. This study was supported by the Swiss Federal Office for the Environment, Section Biotechnology (12.0003.KP / L121-0964), by the Swiss Expert Committee for Biosafety (grant number 04.1240.PZ / Lo64-7521) and by the Swiss Federal Office of Public Health. The views and opinions expressed in this article are those of the authors and do not reflect those of the Swiss Federal Authorities supporting this study.
Conflict of interest

None declared.

Authors' contributions

FCO: performed the experiments, analysed the data, drafted and revised the manuscript. JF: analysed the data and critically revised the manuscript. PP: designed the study, performed the experiments, analysed the data, drafted and revised the manuscript.

\section{References}

1. Johansson A, Tomaso H, Padeshki P, Sjöstedt A, Silman N, Pilo P. Francisella tularensis: Tularemia. In: Elschner M, Cutler Sj, Weidmann M, Butaye P, editors. BSL3 and BSL4 Agents: Epidemiology, Microbiology, and Practical Guidelines. Weinheim: Wiley-Blackwell; 2012.

http://dx.doi.org/10.1002/9783527645114.ch6 http://dx.doi.org/10.1002/9783527645114.ch20

2. Martin C, Gallardo MT, Mateos L, Vián E, García MJ, Ramos J, et al. Outbreak of tularaemia in Castilla y León, Spain. Euro Surveill. 2007;12(45): pii=3302.

3. Kreizinger Z, Makrai L, Helyes G, Magyar T, Erdelyi K, Gyuranecz M. Antimicrobial susceptibility of Francisella tularensis subsp. holarctica strains from Hungary, Central Europe. J Antimicrob Chemother. 2013;68(2):370-3. http://dx.doi.org/10.1093/jac/dks399

4. Georgi E, Schacht E, Scholz HC, Splettstoesser WD. Standardized broth microdilution antimicrobial susceptibility testing of Francisella tularensis subsp. holarctica strains from Europe and rare Francisella species. J Antimicrob Chemother. 2012;67(10):2429-33.

http://dx.doi.org/10.1093/jac/dks238

5. Tomaso H, Al Dahouk S, Hofer E, Splettstoesser WD, Treu TM, Dierich MP, et al. Antimicrobial susceptibilities of Austrian Francisella tularensis holarctica biovar II strains. Int I Antimicrob Agents. 2005;26(4):279-84. http://dx.doi.org/10.1016/j.ijantimicag.2005.07.003

6. Antunes NT, Frase H, Toth M, Vakulenko SB. The Class A $\square$-Lactamase FTU-1 is Native to Francisella tularensis. Antimicrob Agents Chemother. 2012;56(2):666-71. http://dx.doi.org/10.1128/AAC.05305-11

7. García del Blanco N, Gutíerrez Martín CB, de la Puente Redondo VA, Rodríguez Ferri EF. In vitro susceptibility of field isolates of Francisella tularensis subsp. holarctica recovered in Spain to several antimicrobial agents. Res Vet Sci. 2004;76(3):195-8. http://dx.doi.org/10.1016/j.rvsc.2003.12.002

8. Sutera V, Levert M, Burmeister WP, Schneider D, Maurin M. Evolution toward high-level fluoroquinolone resistance in Francisella species. J Antimicrob Chemother. 2014;69(1):101-10. http://dx.doi.org/10.1093/jac/dkt321

9. Johansson A, Farlow J, Larsson P, Dukerich M, Chambers E, Byström $M$, et al. Worldwide genetic relationships among Francisella tularensis isolates determined by multiplelocus variable-number tandem repeat analysis. J Bacteriol. 2004;186(17):5808-18.

http://dx.doi.org/10.1128/JB.186.17.5808-5818.2004

10. Larsson P, Svensson K, Karlsson L, Guala D, Granberg M, Forsman $M$, et al. Canonical insertion-deletion markers fo rapid DNA typing of Francisella tularensis. Emerg Infect Dis. 2007;13(11):1725-32. http://dx.doi.org/10.3201/eid1311.070603

11. Svensson K, Granberg M, Karlsson L, Neubauerova $V$, Forsman M, Johansson A. A real-time PCR array for hierarchical identification of Francisella isolates. PLoS One. 2009;4(12):e8360. http://dx.doi.org/10.1371/journal.pone.0008360

12. Gyuranecz M, Birdsell DN, Splettstoesser W, Seibold E, Beckstrom-Sternberg SM, Makrai L, et al. Phylogeography of Francisella tularensis subsp. holarctica, Europe. Emerg Infect Dis. $2012 ; 18(2): 290-3$. http://dx.doi.org/10.3201/eid1802.111305

13. Vogler AJ, Birdsell D, Price LB, Bowers JR, Beckstrom-Sternberg SM, Auerbach RK, et al. Phylogeography of Francisella tularensis: global expansion of a highly fit clone. J Bacteriol. 2009;191(8):2474-84. http://dx.doi.org/10.1128/JB.01786-08

14. Chanturia G, Birdsell DN, Kekelidze M, Zhgenti E, Babuadze G, Tsertsvadze N, et al. Phylogeography of Francisella tularensis subspecies holarctica from the country of Georgia. BMC 
Microbiol. 2011;11:139.

http://dx.doi.org/10.1186/1471-2180-11-139

15. Vogler AJ, Birdsell DN, Lee J, Vaissaire J, Doujet CL, Lapalus M, et al. Phylogeography of Francisella tularensis ssp. holarctica in France. Lett Appl Microbiol. 2011;52(2):177-80. http://dx.doi.org/10.1111/j.1472-765X.2010.02977.x

16. Dempsey MP, Dobson M, Zhang C, Zhang M, Lion C, GutiérrezMartín CB, et al. Genomic deletion marking an emerging subclone of Francisella tularensis subsp. holarctica in France and the Iberian Peninsula. Appl Environ Microbiol. 2007;73(22):7465-70. http://dx.doi.org/10.1128/AEM.00646-07

17. Pilo P, Johansson A, Frey J. Identification of Francisella tularensis cluster in central and western Europe. Emerg Infect Dis. 2009;15(12):2049-51. http://dx.doi.org/10.3201/eid1512.080805

18. Müller W, Hotzel H, Otto P, Karger A, Bettin B, Bocklisch H, et al. German Francisella tularensis isolates from European brown hares (Lepus europaeus) reveal genetic and phenotypic diversity. BMC Microbiol. 2013;13:61. http://dx.doi.org/10.1186/1471-2180-13-61

19. Gehringer H, Schacht E, Maylaender N, Zeman E, Kaysser $P$, Oehme R, et al. Presence of an emerging subclone of Francisella tularensis holarctica in Ixodes ricinus ticks from south-western Germany. Ticks Tick Borne Dis. 2013;4(1-2):93100. http://dx.doi.org/10.1016/j.ttbdis.2012.09.001

20. Kudelina RI, Olsufiev NG. Sensitivity to macrolide antibiotics and lincomycin in Francisella tularensis holarctica. J Hyg Epidemiol Microbiol Immunol. 1980;24(1):84-91.

21. Dentan C, Pavese P, Pelloux I, Boisset S, Brion JP, Stahl JP, et al. Treatment of tularemia in pregnant woman, France. Emerg Infect Dis. 2013;19(6):996-8. http://dx.doi.org/10.3201/eid1906.130138

22. Maho A, Rossano A, Hächler H, Holzer A, Schelling E, Zinsstag $J$, et al. Antibiotic susceptibility and molecular diversity of Bacillus anthracis strains in Chad: detection of a new phylogenetic subgroup. J Clin Microbiol. 2006;44(9):3422-5. http://dx.doi.org/10.1128/JCM.01269-06

23. Wicki R, Sauter P, Mettler C, Natsch A, Enzler T, Pusterla N, et al. Swiss Army Survey in Switzerland to determine the prevalence of Francisella tularensis, members of the Ehrlichia phagocytophila genogroup, Borrelia burgdorferi sensu lato, and tick-borne encephalitis virus in ticks. Eur J Clin Microbiol Infect Dis. 2000;19(6):427-32. http://dx.doi.org/10.1007/s100960000283

24. Broekhuijsen $M$, Larsson $P$, Johansson A, Bystrom M, Eriksson $\mathrm{U}$, Larsson E, et al. Genome-wide DNA microarray analysis of Francisella tularensis strains demonstrates extensive genetic conservation within the species but identifies regions that are unique to the highly virulent $F$. tularensis subsp. tularensis. J Clin Microbiol. 2003;41(7):2924-31. http://dx.doi.org/10.1128/JCM.41.7.2924-2931.2003

25. Byström M, Böcher S, Magnusson A, Prag J, Johansson A. Tularemia in Denmark: identification of a Francisella tularensis subsp. holarctica strain by real-time PCR and high-resolution typing by multiple-locus variable-number tandem repeat analysis. J Clin Microbiol. 2005;43(10):5355-8. http://dx.doi.org/10.1128/JCM.43.10.5355-5358.2005

26. Clinical and Laboratory Standards Institute (CLSI). Approved standard Mo7-A8. In: Methods for dilution antimicrobial susceptibility tests for bacteria that grow aerobically. 8 th ed. Wayne: CLSI; 2009;29(2).

27. Clinical and Laboratory Standards Institute (CLSI). Approved guideline M45-A2. In: Methods for antimicrobial dilution and disk susceptibility testing of infrequently isolated or fastidious bacteria. 2 nd ed. Wayne: Clinical and Laboratory Standards Institute; 2010;30(18).

28. Bina XR, Wang C, Miller MA, Bina JE. The Blaz beta-lactamase from the live-vaccine strain of Francisella tularensis encodes a functional protein that is only active against penicillin-class beta-lactam antibiotics. Arch Microbiol. 2006;186(3):219-28. http://dx.doi.org/10.1007/s00203-006-0140-6

29. Gestin B, Valade E, Thibault F, Schneider D, Maurin M. Phenotypic and genetic characterization of macrolide resistance in Francisella tularensis subsp. holarctica biovar I. J Antimicrob Chemother. 2010;65(11):2359-67. http://dx.doi.org/10.1093/jac/dkq315

30. Splettstoesser WD, Mätz-Rensing K, Seibold E, Tomaso H, Al Dahouk S, Grunow R, et al. Re-emergence of Francisella tularensis in Germany: fatal tularaemia in a colony of semifree-living marmosets (Callithrix jacchus). Epidemiol Infect 2007; 135(8):1256-65. http://dx.doi.org/10.1017/S0950268807008035

31. Svensson K, Back E, Eliasson H, Berglund L, Granberg M, Karlsson L, et al. Landscape epidemiology of tularemia outbreaks in Sweden. Emerg Infect Dis. 2009;15(12):1937-47. http://dx.doi.org/10.3201/eid1512.090487

32. Karlsson E, Svensson K, Lindgren P, Byström M, Sjodin A, Forsman $M$, et al. The phylogeographic pattern of Francisella tularensis in Sweden indicates a Scandinavian origin of Eurosiberian tularaemia. Environ Microbiol. 2013;15(2):634-45. http://dx.doi.org/10.1111/1462-2920.12052

33. Abril C, Nimmervoll H, Pilo P, Brodard I, Korczak B, Seiler M, et al. Rapid diagnosis and quantification of Francisella tularensis in organs of naturally infected common squirrel monkeys (Saimiri sciureus). Vet Microbiol. 2007;127(1-2):203-8. http://dx.doi.org/10.1016/j.vetmic.2007.08.006

34. Valade E, Vaissaire J, Mérens A, Hernandez E, Gros C, Le Doujet $C$, et al. Susceptibility of 71 French isolates of Francisella tularensis subsp. holarctica to eight antibiotics and accuracy of the Etest method. J Antimicrob Chemother. 2008;62(1):208 10 . http://dx.doi.org/10.1093/jac/dkn146

35. Baker CN, Hollis DG, Thornsberry C. Antimicrobial susceptibility testing of Francisella tularensis with a modified Mueller-Hinton broth. J Clin Microbiol. 1985;22(2):212-5.

36. Enderlin G, Morales L, Jacobs RF, Cross JT. Streptomycin and alternative agents for the treatment of tularemia: review of the literature. Clin Infect Dis. 1994;19(1):42-7. http://dx.doi.org/10.1093/clinids/19.1.42

37. Tärnvik A, Chu MC. New approaches to diagnosis and therapy of tularemia. Ann N Y Acad Sci. 2007;1105:378-404. http://dx.doi.org/10.1196/annals.1409.017

38. Penn RL, Kinasewitz GT. Factors associated with a poor outcome in tularemia. Arch Intern Med. 1987;147(2):265-8. http://dx.doi.org/10.1001/archinte.1987.00370020083041 http://dx.doi.org/10.1001/archinte.147.2.265

39. Pérez-Castrillón JL, Bachiller-Luque P, Martín-Luquero M, Mena-Martín FJ, Herreros V. Tularemia epidemic in northwestern Spain: clinical description and therapeutic response. Clin Infect Dis. 2001;33(4):573-6. http://dx.doi.org/10.1086/322601

40. Johansson A, Berglund L, Gothefors L, Sjöstedt A, Tärnvik A. Ciprofloxacin for treatment of tularemia in children. Pediatr Infect Dis J. 2000;19(5):449-53. http://dx.doi.org/10.1097/00006454-200005000-00011

41. Scheel O, Hoel T, Sandvik T, Berdal BP. Susceptibility pattern of Scandinavian Francisella tularensis isolates with regard to oral and parenteral antimicrobial agents. APMIS. 1993;101(1):33-6. http://dx.doi.org/10.1111/j.1699-0463.1993.tboo077.x

42. Ikäheimo I, Syrjälä H, Karhukorpi J, Schildt R, Koskela M. In vitro antibiotic susceptibility of Francisella tularensis isolated from humans and animals. J Antimicrob Chemother. 2000;46(2):287-90. http://dx.doi.org/10.1093/jac/46.2.287

43. García Del Blanco N, Gutiérrez CB, De La Puente V, Rodríguez Ferri EF. Biochemical characterisation of Francisella tularensis strains isolated in Spain. Vet Rec. 2004;154(2):55-6. http://dx.doi.org/10.1136/vr.154.2.55

44. Johansson A, Urich SK, Chu MC, Sjöstedt A, Tärnvik A. In vitro susceptibility to quinolones of Francisella tularensis subspecies tularensis. Scand J Infect Dis. 2002;34(5):327-30. http://dx.doi.org/10.1080/00365540110080773 